\title{
EXPERIENCES OF TREATMENT WITH PAVLIK'S BANDAGE FOR CONGENITAL DISLOCATION OF THE HIP IN INFANTS
}

\author{
SEIKEI MIYAGI, TEIJI YANO, YASUHIRO IWANAGA \\ AND TETSUKO OKUNO \\ Department of Orthopedic Surgery, Kurume University School \\ of Medicine, Kurume, Japan
}

(Received for publication March 12, 1973)

\begin{abstract}
During 5 years from 1966 to 1970, 364 hips (208 CDH and 156 subluxation) in 291 infants ( 47 males and 244 females) less than 12 months of age were treated with Pavlik's bandage. The reduction was failed in 28 dislocated hips in 3 males and 22 females.

Follow-up results after 1 to 5 years were obtained in $100 \mathrm{CDH}$ and 87 subluxations, being satisfactory in 178 hips $(95.7 \%)$ and poor in 3 dislocated hips. Out of 28 unreduced hips, the follow-up results were obtained in 17 , being satisfactory in $83 \%$.

The authors concluded that Pavlik's bandage is a reliable method for CDH in young infants and superior to Lorenz's method or Frejka's splint.
\end{abstract}

Before 1966, congenital dislocation of the hip (CDH) and subluxation had been treated in our clinic by Lorenz's method, Frejka's splint ${ }^{11}$ or modified David's method ${ }^{2}$, and the follow-up results were unsatisfactory. Since 1966, Pavlik's bandage ${ }^{3)}$ was applied for $\mathrm{CDH}$ and subluxation in infants less than one year of age, and the short term results were encouraging. The authors present their experiences of treatment with Pavlik's bandage.

\section{OUR BANDAGE AND METHOD OF TREATMENT :}

Considering the water tolelancy, our bandage was made of vinyl so as to be able to take a bath with it (Fig. 1). After the bandage was applied to the infants whoes hips were flexed (Fig. 2), $\mathrm{X}$-ray check was carried out every one week until the hip could be rduced. After reduction, the hip was checked by X-ray every one month for 3 or 4 times, and the bandage was removed, if the development of the hip seemed to be normal. Follow-up checks were carried out at beginning of walk, 3 and 5 years of age.

If the reduction could not be achieved 3 or 4 weeks after application of the bandage, the bandage was removed and the leg was allowed to move freely for one month. Then the hip was reduced by gentle manipulation and set in plaster cast of Lorenz's position. After the plaster fixation for one month, Pavlik's bandage was applied as mentioned above. The cases of false reduction diagnosed by arthrography were also treated by the same way of treatment as unreduced cases.

\section{SURVEY OF CASES :}

During 5 years from 1966 to 1970, 364 hips (208 $\mathrm{CDH}$ and 156 subluxation) 


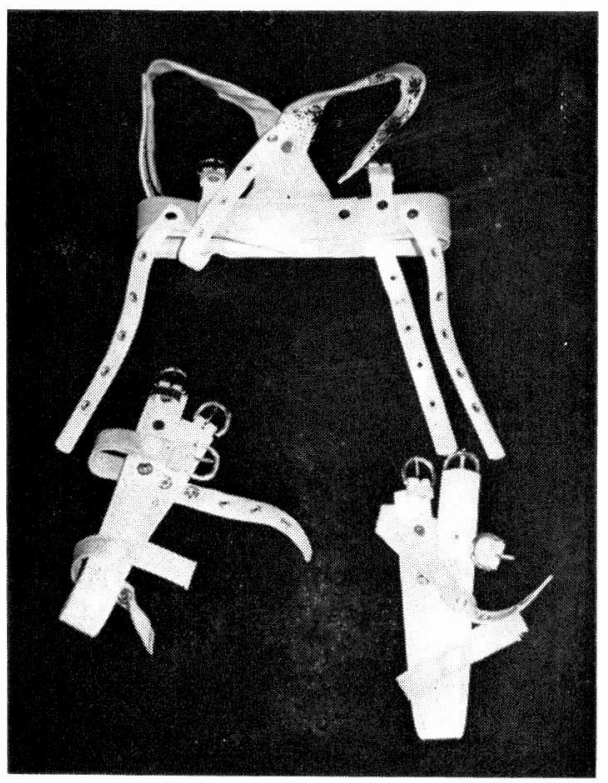

Fig. 1

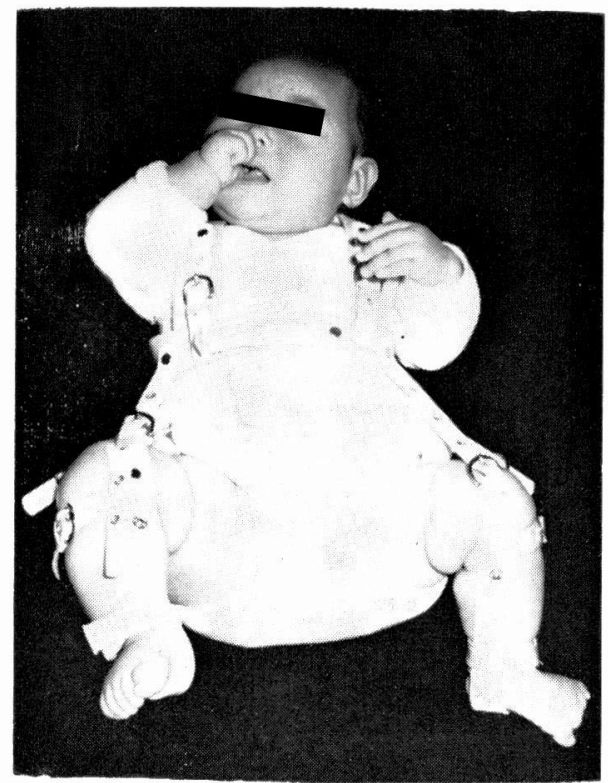

Fig. 2

TABLE 1

Joint affected

\begin{tabular}{c|c|ccc|c}
\hline $\begin{array}{c}\text { Grade of } \\
\text { dislocation }\end{array}$ & Subluxation & Dislocation & (Unreduced & \%) & Total \\
Months of age & 2 & 2 & 1 & 50.0 & 4 \\
$1-$ & 7 & 26 & 7 & 27.0 & 33 \\
$2-$ & 38 & 37 & 5 & 13.5 & 75 \\
$3-$ & 37 & 52 & 3 & 5.8 & 89 \\
$4-$ & 35 & 41 & 3 & 7.3 & 76 \\
$5-$ & 22 & 20 & 3 & 15.0 & 42 \\
$6-$ & 8 & 17 & 5 & 29.4 & 25 \\
$7-$ & 4 & 8 & 1 & 12.5 & 3 \\
$8-$ & 1 & 1 & 0 & & 3 \\
$11-$ & & 2 & & & 2 \\
\hline
\end{tabular}

-n 291 infants (47 males and 244 females) less than 12 months of age were treated with Pavlik's bandage (Table 1). In $87 \%$ of the cases, the treatment started within 6 months of age.

Twenty eight dislocated hips in 3 males and 22 females were failed to reduce, but no caes of subluxation. As to the months of age, 4 or 5 were favorable, being unfavorable 1 or 2 (Table 2). Fourteen hips were impossible to be reduced, and the treatment with the bandage was cancelled in 2 weeks for 3 hips and 4 weeks for 11 hips. The 
TABLE 2

Results

\begin{tabular}{|c|c|c|c|c|c|c|c|c|c|c|}
\hline \multirow{2}{*}{$\begin{array}{l}\text { Months } \\
\text { of Age }\end{array}$} & \multicolumn{4}{|c|}{ Dislocation } & \multicolumn{4}{|c|}{ Subluxation } & \multirow{2}{*}{ Total } & \multirow{2}{*}{$(\%)$} \\
\hline & $1-3$ & $4-6$ & $7-$ & Total & $1-3$ & $4-6$ & $7-$ & Total & & \\
\hline Excellent & 24 & 37 & 6 & 67 & 19 & 50 & 5 & 74 & 141 & 75.4 \\
\hline Good & 8 & 15 & 4 & 27 & 3 & 7 & 1 & 11 & 38 & 20.3 \\
\hline Fair & 1 & 1 & 1 & 3 & 1 & 1 & 0 & 2 & 5 & 2.7 \\
\hline Poor & 1 & 1 & 1 & 3 & 0 & 0 & 0 & 0 & 3 & 1.6 \\
\hline Total & 34 & 54 & 12 & 100 & 23 & 58 & 6 & 87 & 187 & 100 \\
\hline
\end{tabular}

remaining 14 hips were thought to be false reduction, showing concentric reduction during application of the bandage and re-dislocation in extended position of the hip after 2 or 3 months of the treatment.

In 180 dislocated hips excluding unreduced 28 hips, the reduction was achieved within 1 or 2 weeks in 155 hips (86.1\%), and 3 or 5 weeks in 25 hips (13. $9 \%)$.

\section{RESULTS :}

Follow-up results 1 to 5 years after removal of the bandage were obtained in $100 \mathrm{CDH}$ and 87 subluxation. The results were evaluated by the last $\mathrm{X}$ ray findings as follows:

Excellent: Anatomical

Good : Slight deformities which can be expected normal developing.

Fair : Moderate deformities which can be improved spontaneously or by treatment.

Poor : Marked deformities, in which abnormal developing is unavoidable.

Ninety four hips (94\%) out of 100 $\mathrm{CDH}$ showed excellent and good results, and 85 hips $(97.9 \%)$ out of 87 subluxation : as a total, satisfactory results were obtained in 178 hips (95.7\%) out of 187 (Table 2). As to the months of age when beginning the treatment, 7 to 11 months were slightly unfavorable, being satisfactory in 10 hips (83.3\%) out of 12 .

For the unreduced 28 hips, 8 were treated by Lorenz's method, 18 by Lorenz's method followed by Pavlik's bandage and one aditional osteotomy, and 2 by operative reduction and osteotomy. Out of these 28 hips, 17 hips could be re-examined after 1 to 3 years, showing the satisfactory results in 14 hips (82.3\%).

Summarazing the follow-up results, satisfactory results were obtained in 108 hips $(92.3 \%)$ out of $117 \mathrm{CDH}$, and in $193(94.6 \%)$ out of $204 \mathrm{CDH}$ and subluxations.

\section{INTERESTING CASES}

Case I : (Fig. 3, a - e)

Pavlik's bandage was applied at 4 months of age. The reduction was not achieved at 1 week and it was succeeded at 2 weeks. The treatment was continued for 4 months when the ossification center of the femoral head was smaller than that of the sound side. At the age of 2 years, the ossification center was still a little smaller, but at the age of 4 years, the hip was revealed to be same as the sound side. The result was evaluated as excellent.

Case 2 : (Fig. 4. a - d)

Pavlik's bandage was applied at 7 
months of age. At one week X-ray check, the hip was reduced, and the treatment was continued for 6 months. When removing the bandage, residual subluxation and hypoplasia of the acetabular roof were detected, and at the age of 3 and a half years, X-ray revealed the enlarged femoral head and hypoplasia of the acetabular roof. The result was evaluated as fair.

Case 3: (Fig. 5, a-d)

Pavlik's bandage was applied at the age of 3 months and continued for 4 months. While the clinical coarses were thought to be good, marked epiphysitis was detected by X-ray check at the age of 1 year and 10 months, which remained still at the age of 3 years and 5 months. The result was evaluated as poor. This is the only one case, in which the marked epiphysis occurred.

Case 4: (Fig. 6, a-d)

Bilateral $\mathrm{CDH}$ was treated by Pavlik's bandage for 3 months from the age of 3 months. During the treatment, the hips were being reduced, but redislocation was detected when removing the bandage. The arthrogram taken after one month revealed interposition which indicated the false reduction.

The hips were reduced manually and fixed in Lorenz's position for one month followed by Pavlik's bandage for 3 months. X-ray at the age of 3 years and 5 months showed a slight hypoplasia of the right hip and the normal left hip. The result of the right hip was evaluated as good and the left excellent.

Case 5 : (Fig. 7, a - d)

Pavlik's bandage was applied at the age of 6 months, but the reduction was failed. After one month, the hip was reduced manually and set in plaster cast of Lorenz's position for one month followed by Pavlik's bandage for 3 months. As a slight epiphysitis of the femoral head and residual subluxation were found, varus-detorsion osteotomy combined with acetabuloplasty was carried out at the age of 1 year and 4 months. X-ray findings at the age of 4 years were evaluated as good.

\section{DISCUSSION}

It is well known that the results of treatment by Lorenz's method or modified one for $\mathrm{CDH}$ are unsatisfactory, even if they were indicated for young infants.

In our clinic, Iwanaga ${ }^{4)}$ presented the follow-up results of over 10 years in the cases under the age of one year treated by the classical methods. Out of 149 subluxations and 78 dislocations, satisfactory results were obtained in 117 hips $(78.5 \%)$ and $52(66.7 \%)$, respectively. He concluded too that hypoplasia of the acetabular roof and lateralization of the femoral head tended to be spontaneously improved and the most important factor for unsatisfactory results was epihysitis of the femoral head.

Concerning Pavlik's bandage, the results of treatment had been recognized by many authors ${ }^{5)-7)}$ to be superior to other methods. In Japan ${ }^{8)-11)}$, Pavlik's bandage becomes popular as a method of choice for $\mathrm{CDH}$ in young infants, and it was noticed that epiphysitis of the femoral head develops only in a few cases.

In our series of $100 \mathrm{CDH}$ and 87 subluxations, the fair results were obtained in 5 hips and the poor in 3 dislocated hips. As the hips with fair result showing the slight epiphysitis can be improved spontaneously or by operative intervention, abnormal developing of the hip was thought to be unavoidable in the 3 hips.

Accrding to Pavlik ${ }^{3)}$ (1957), the reduction was failed in $101(16.0 \%)$ out of 632 dislocated hips. In our series of 208 dislocated hips under the age of 
one year, the reduction was failed in 28 (13.5\%). Although our data may not always be concluded to be satisfactory, the reduction would become more successful, if the bandage is applied more cautiously.

As the reduction is failed in a few cases, treatments and piognosis of the unreduced cases are important problems. Our 28 unreduced hips were treated by Lorenz's method or plaster fixation in Loranz's positon for one month followed by Pavlik's bandage, and the results were satisfactory in $83 \%$ as mentioned. Therefore, Pavlik's bandage is thought to be a reliable method of treatment for $\mathrm{CDH}$ and be superior to Lorenz's method or Frejka's splint.

\section{REFERENCES}

1) Ilfeld, F. W.: The management of congenital dislocation and dysplasia of the hip by means of special splint. J. Bone Jt. Surg., 39, 99, 1957.

2) David, B. : Zur Behandlung der flachdysplastischen Hüftpfanne durch beiseitigen Unterschenkelgips mit abduzierendem Stab. Z. Orthop., 83, 819, 1953.
3) PAVLIK, A. : Die funktionelle Behandlungsmethode mittels Riemenbügel als Prinzip der Konservation. Z. Orthop., 89, 341, 1957.

4) IWANAGA, Y.: A follow-up study with special reference to prognosis of residual subluxation. J. Kurume Med. Ass., 32, 239, 1969.

5) DörR, W. M. : Erfahrungen mit dem Riemebügel nach Pavlik in der Behandlung der sog. angeborenen Hüftgelenksluxation und ihr Vorstufen. Z. Orthop., 101, 535, 1966.

6) Glauber, A. : Ergebnisse der Behandlung der angeborenen Hüftgelenksluxation mit dem Riemenbügel nach Pavlik. Z. Orthop., 101, 108, 1972.

7) Mittelmeyer, H. : Beitrag zur funktionellen Therapie und Spontanreposition der angeborenen Luxationshüfte mit Spreizhöschen und Pavlikbanage. Arch. Orthop. Unfallchir., 52, 465, 1961.

8) Fujimoto, K. : Functional treatment of CDH. Clinical Orthopedic Surg., 2, 219, 1967.

9 ) Nakamura, S. : Experiences of Riemenbügel method for CDH. Orthopedic Surgery, 16, 770, 1965.

10) Suzuki, R. : Early Treatment of CDH. Orthopedic Surgery, 17, 169, 1966.

11) SAKAGUCHI, R. : Treatment of CDH in early infants. Clinical Orthopedic Surgery, 2, 697, 1967. 
Fig. 3: Case 1

a : 4-months-old female

b: after one week
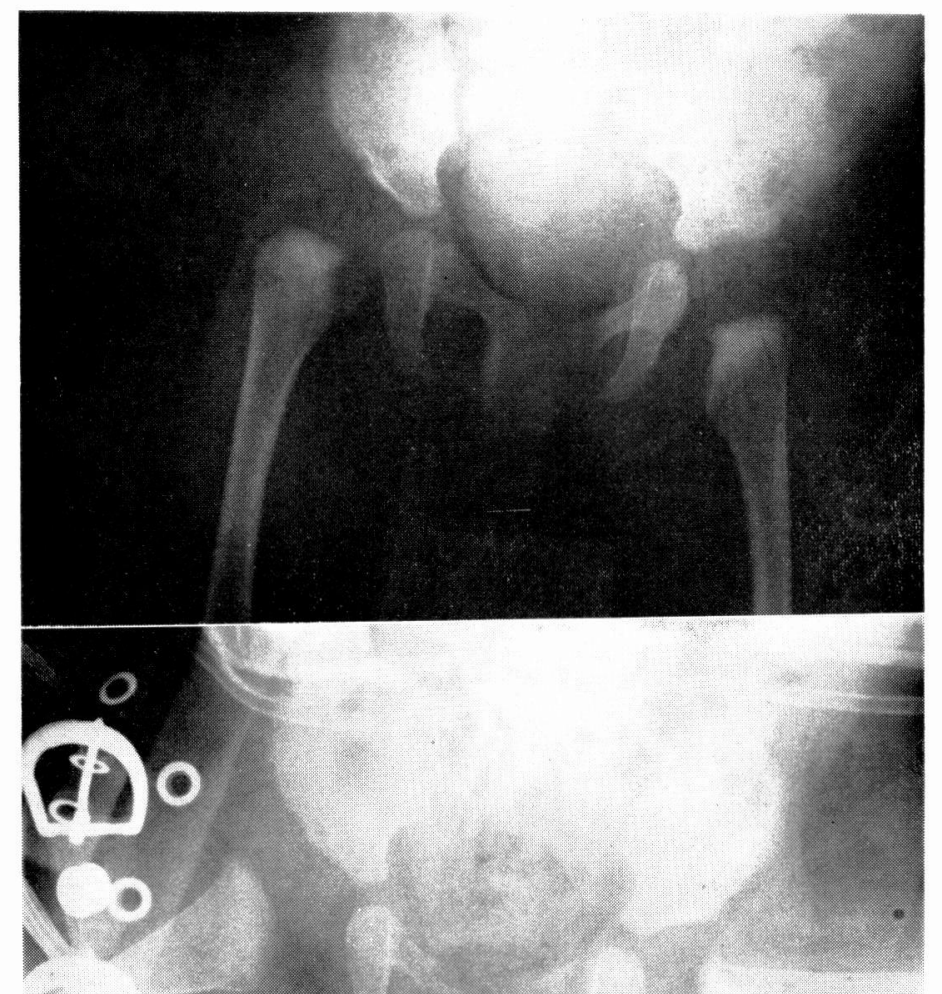

c : after 4 months

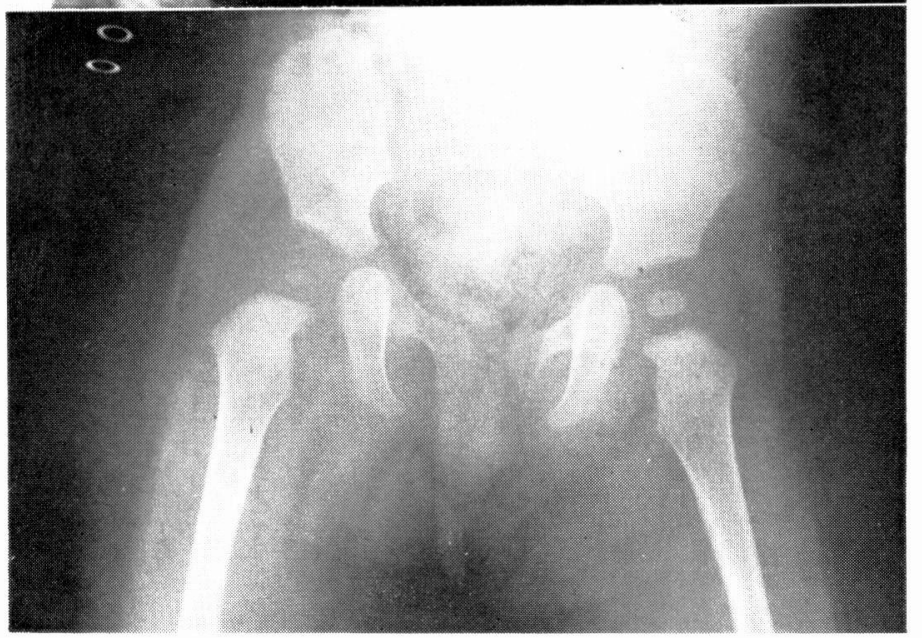


d : 2 years of age

e : 4 years of age

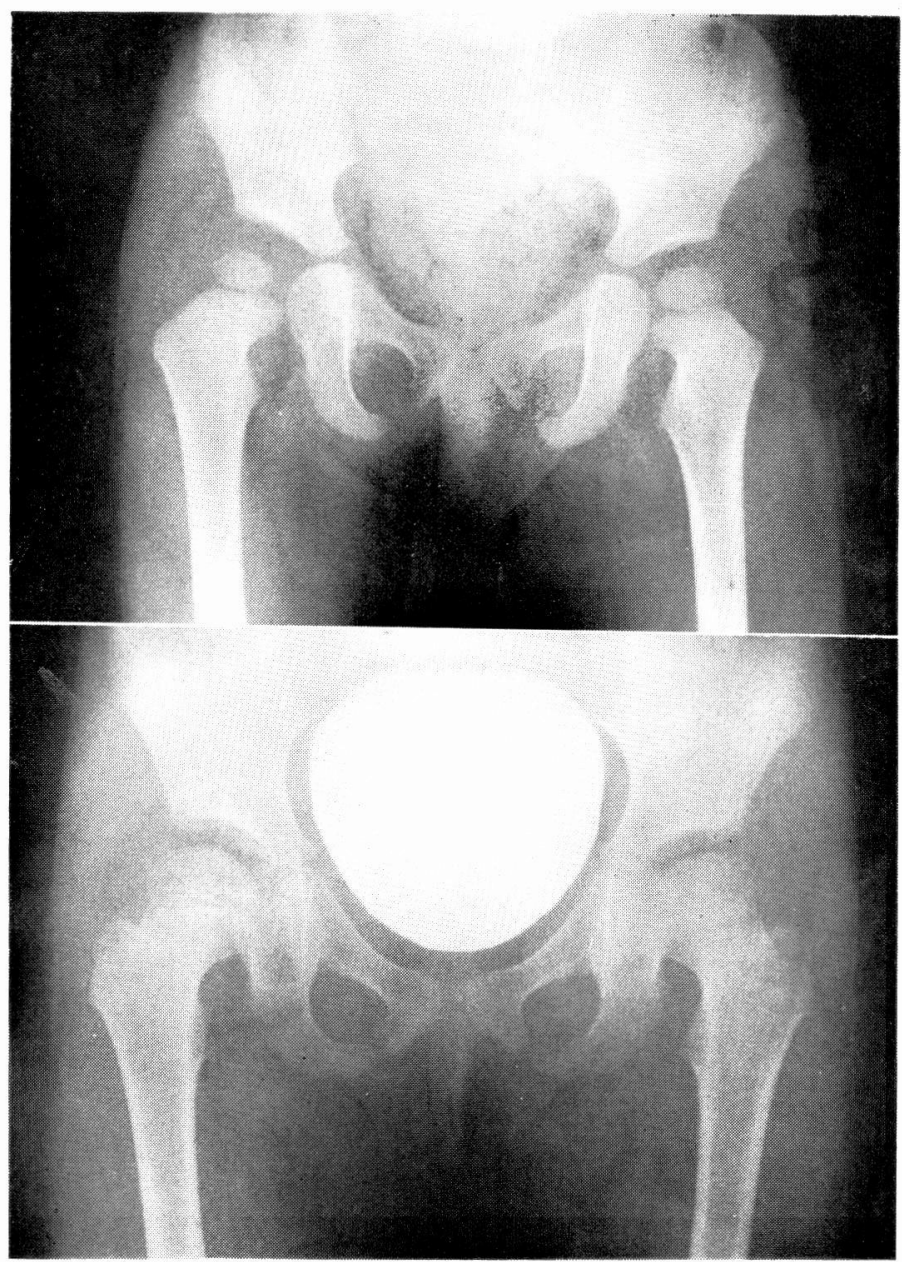


Fig. 4: Case 2

a : 7-months-old female

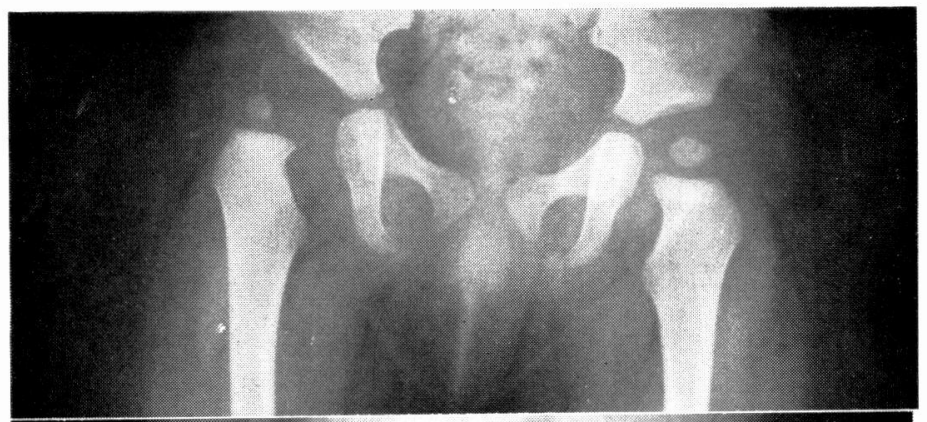

b : after one week

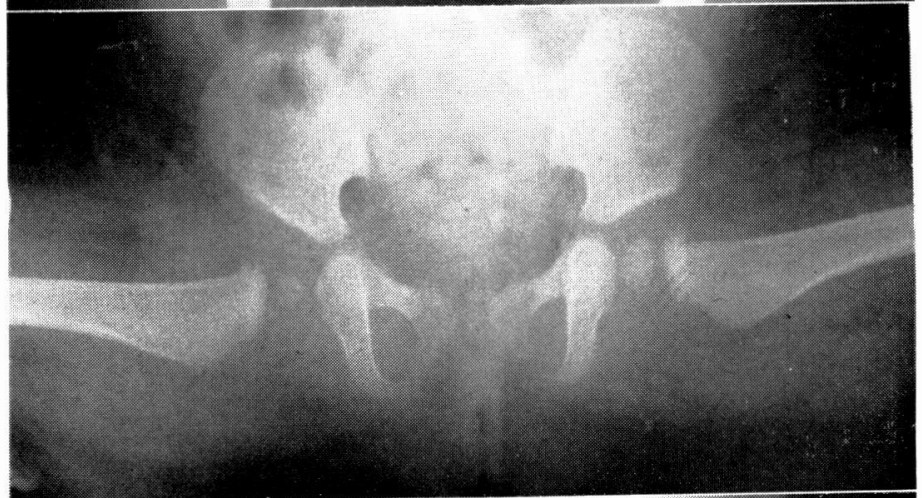

c : one year and

3 months of age

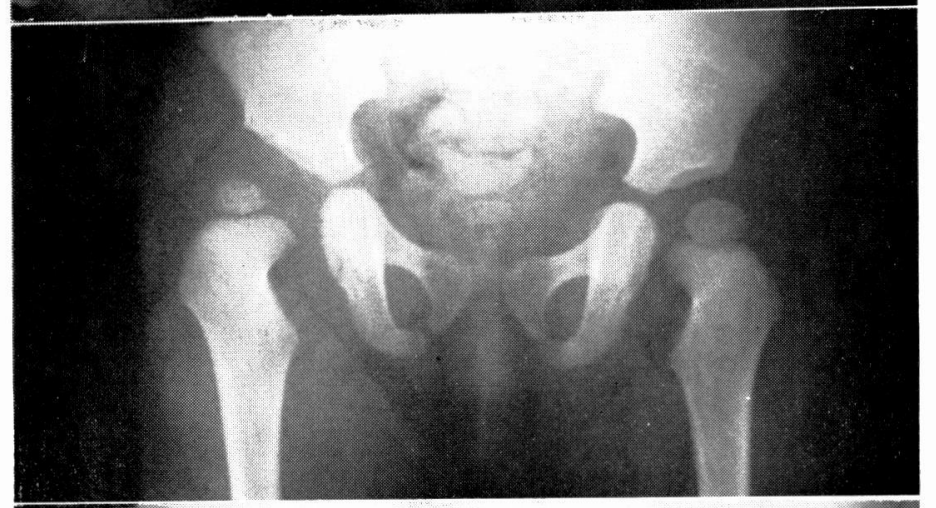

d: 3 years and

6 months of age

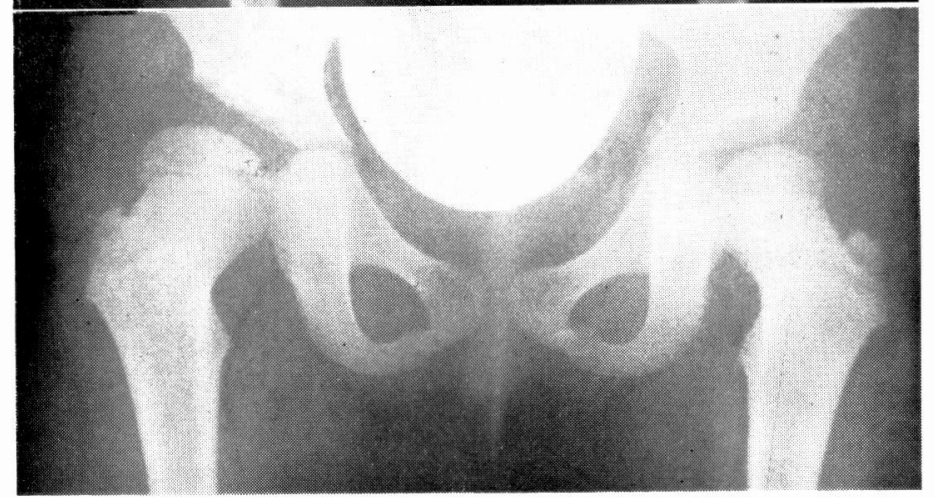


Fig. 5 : Case 3

a : 3-months-old female
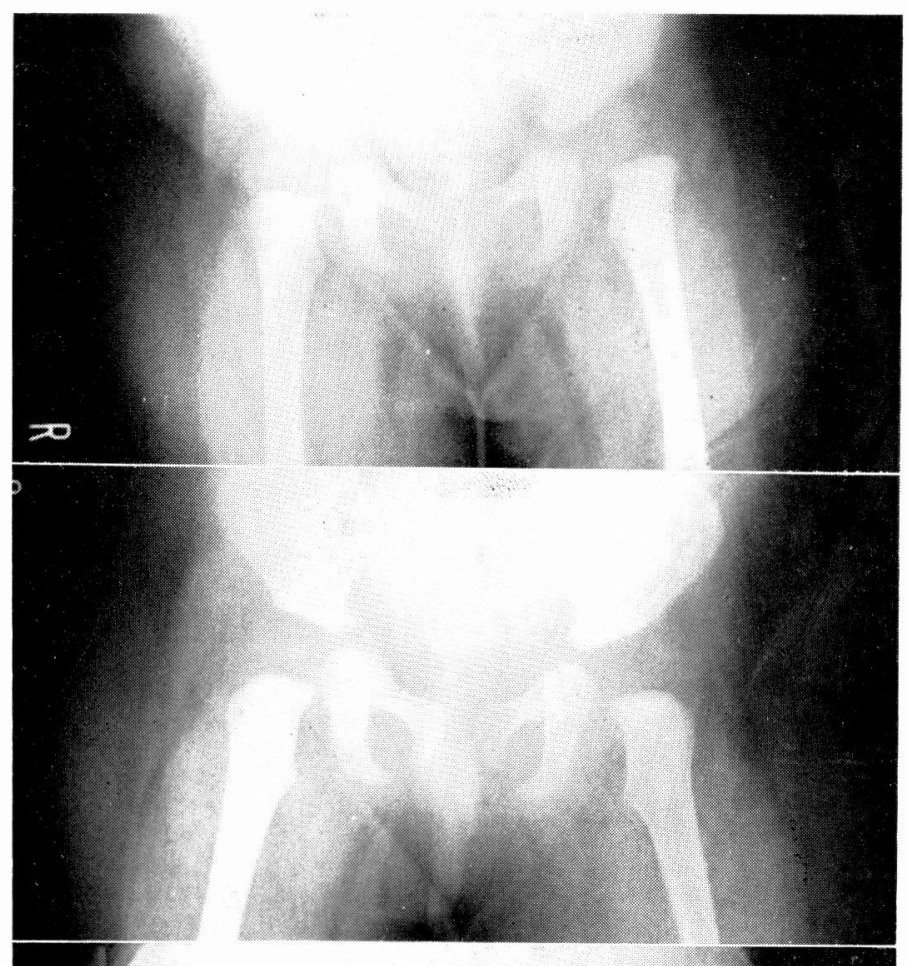

b: after 4 months

c : one year and

10 months of age

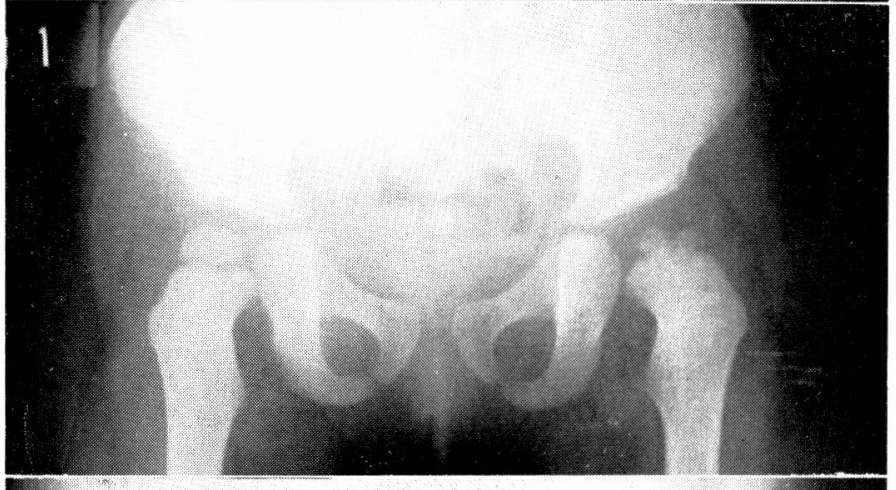

d : 3 years and

5 months of age
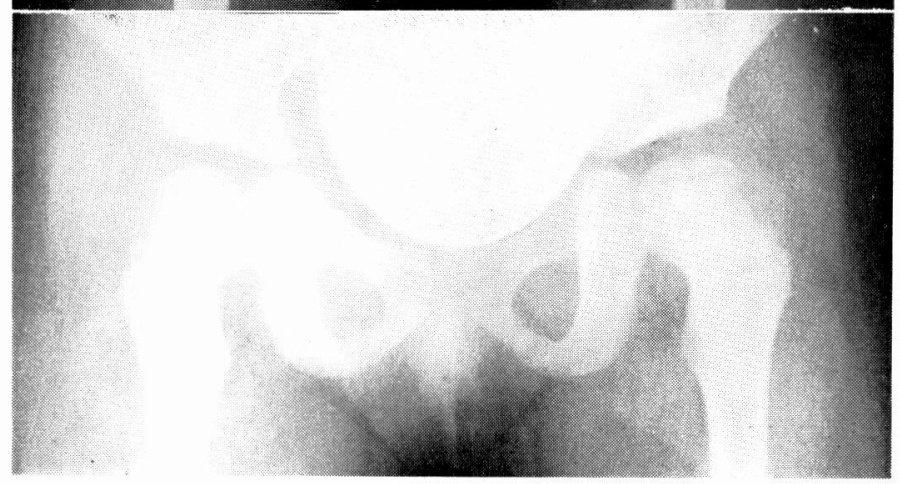
Fig. 6 : Case 4

a : 3-months-old female

b : 7 months of age

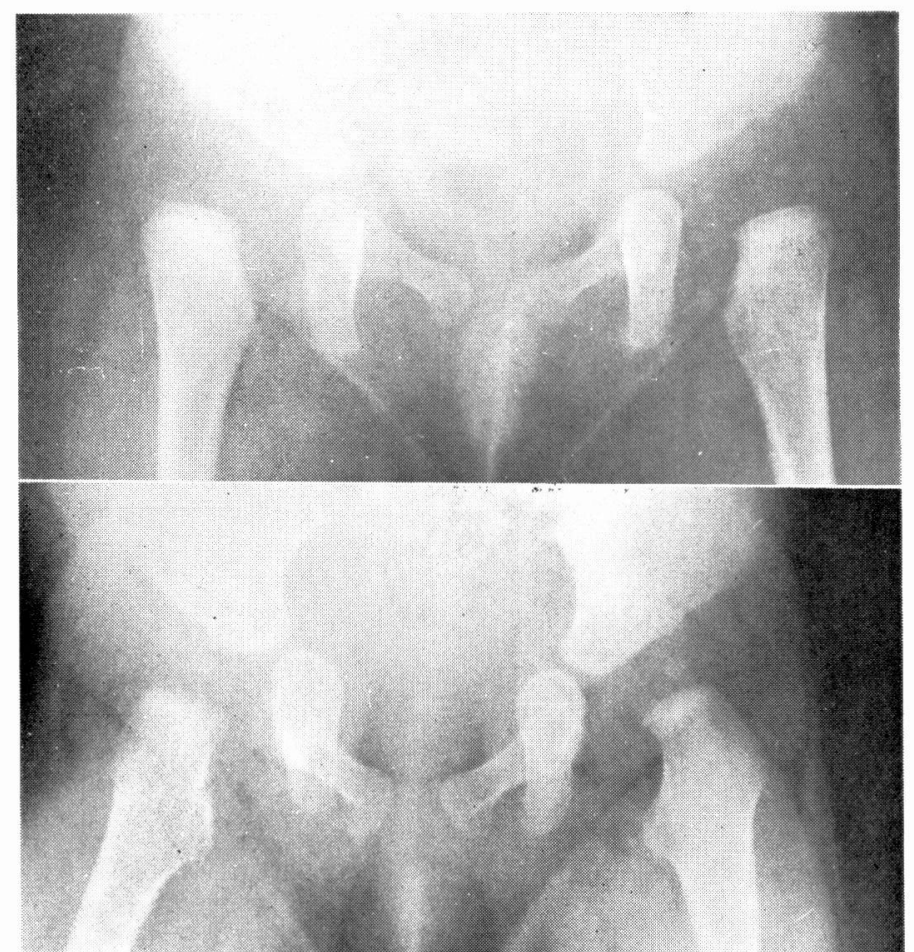

c : arthrogram at

8 months of age

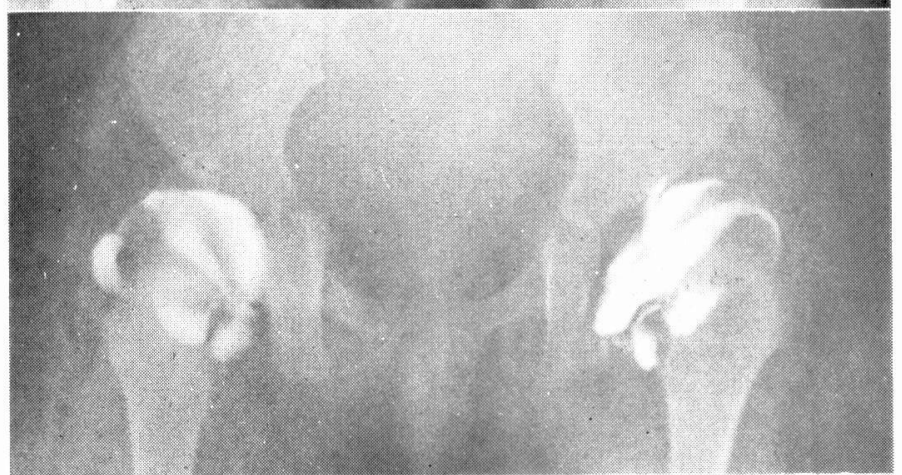

d: 3 years and 5 months

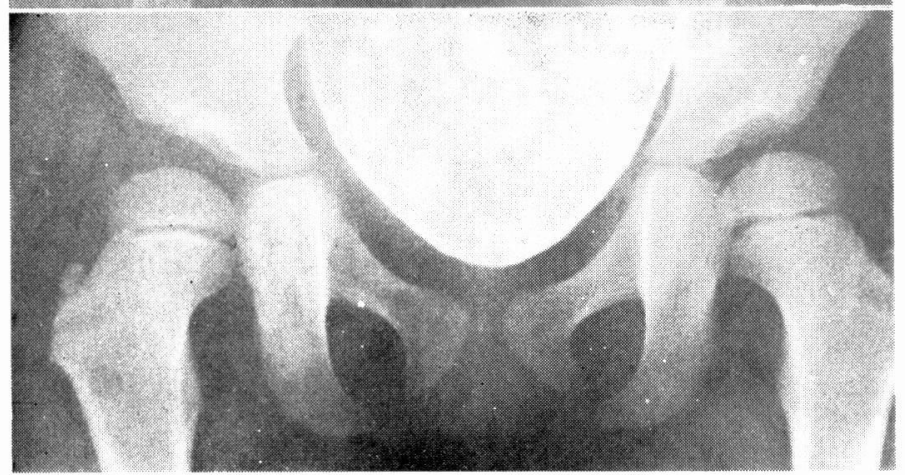


Fig. 7 : Case 5

a: 6-months-old-female

$b$ : one year of age

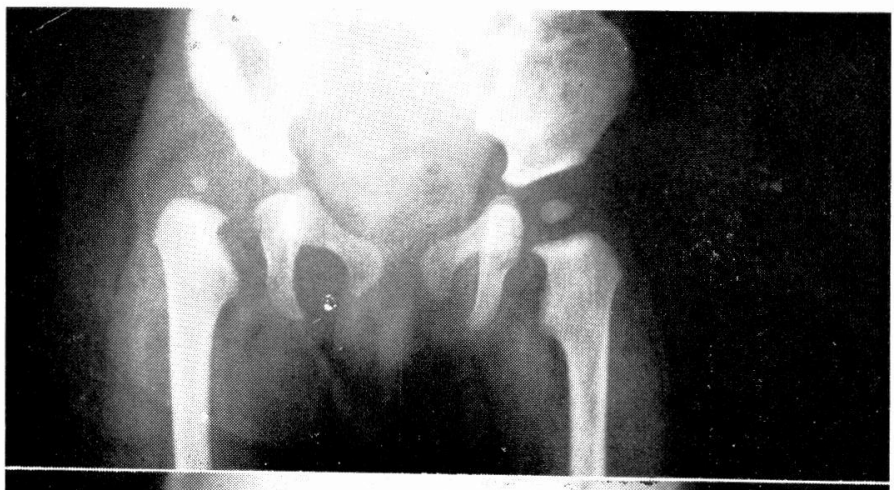

c : one year and 4 months of age
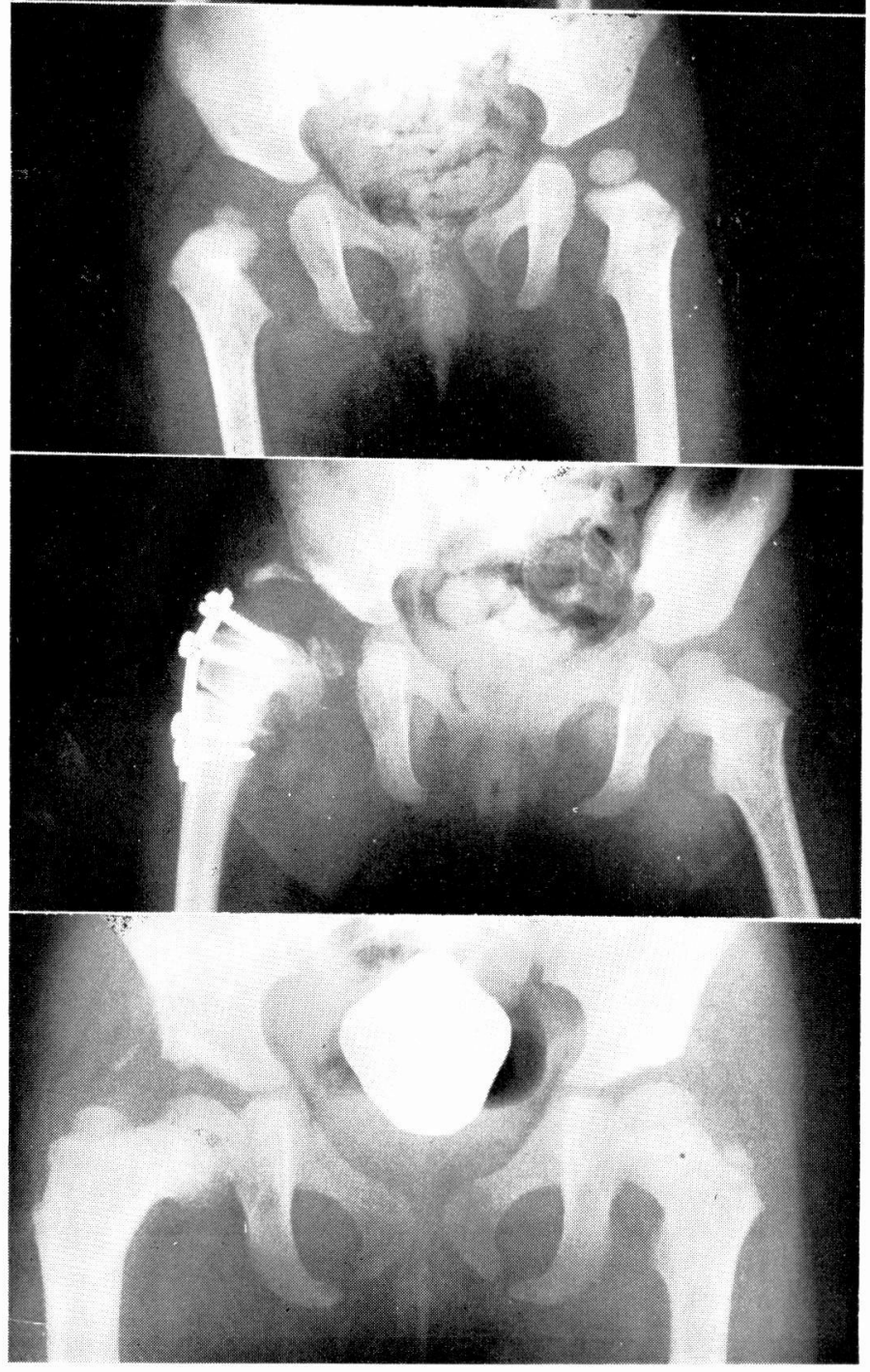